\title{
VERSATILE, EFFICIENT AND LONG WAGON FOR INTERMODAL TRANSPORT IN EUROPE
}

This contribution describes the efforts of the multidisciplinary team of University of Zilina in answering the EC FP7 Call for project proposals FP7-SST-2010-RTD-1 SST.2010.2.1-1: Fast implementation of innovative/effective rail technologies to improve rail freight services. The results of the project "VEL-Wagon - Versatile, Efficient and Long Wagon for Intermodal Transport in Europe", approved under the grant No. 265610 should be a key milestone for the efficiency of intermodal freight wagons, since it demonstrated that fewer elements and less dead weight can result in the same or even better transport output, saving material, energy, environment and thus provide more efficient means for transport.

Keywords: Rail freight, intermodal transport, wagon concept development, multipurpose wagon platform, longer and lighter wagon, dead weight reduction, efficiency of wagon use, capacity increase, market needs.

\section{Introduction}

The objective of the EC FP7 2010 Call [1] in Area 7.2.2.1Logistics and intermodal transport was to improve transport efficiency between and within different modes while recognising their complementarities within a transport system. It included activities for the development of high quality logistics, covering all transport modes. Intermodality in passengers and freight was addressed by activities including seamless and competitive solutions, and, integration of transport hubs (terminals, stations, ports, etc.) in all transport modes.

Among the expected impacts among others was also:

- Maximisation of the cargo capacity of vehicles and vessels within intermodal door-to-door transportation routes,

- Optimisation of logistics services, transportation flows, terminal and infrastructure capacity within European and global supply chains.

The aim of the research under the sub-topic SST.2010.2.1-1"Fast implementation of innovative/effective rail technologies to improve rail freight services", was to develop technologies and solutions to improve competitiveness of rail freight.

To fulfil these expectations, a project consortium, led by the Technical University of Berlin (TUB) and including participants from the Royal Institute of Technology in Stockholm (KTH), University of Zilina (UNIZA) and Tatravagonka Poprad (TVP), was formed. The proposed project with the name concerned the design of a versatile platform element for a multipurpose function and intermodal use that could bring an important gain of flexibility, accessibility and efficiency of rail freight services.

It investigated the current status of the European freight railway market and, more importantly, it took a look at the trend thereof and its associated logistics. In synchronisation, a wagon engineering activity was launched, for determining the final costs of a solution matching the market requirements.

The project with the name "Versatile, Efficient and Long Wagon for Intermodal Transport in Europe" and acronym "VEL-WAGON" (2011-2012) examined the limits of light wagon construction and the future infrastructure response to the everyday-more-challenging railway traffic (www.vel-wagon.eu ). The investigation was initiated with concrete wagon concepts to be examined, namely, 4-axle rigid platforms of $24.384 \mathrm{~m}$ to $27,432 \mathrm{~m}$ ( $80 \mathrm{ft}$ to $90 \mathrm{ft}$ ) length. The outcome was a compromised solution between economic aspects and technical constraints.

\section{The analysis}

The project was targeting the above mentioned concepts by analysing the future necessities on light and versatile wagons that will deploy better performance and quality to compete against the road. The basic idea of VEL-Wagon was that in the future longer loading surfaces without interruptions, as well as more capable platforms with higher axle loads and with lower loading heights will be necessary to increase the capacity of the freight railway transportation. This can be understood as the current trend follow

\footnotetext{
* Peter Fabian ${ }^{1}$, Juraj Gerlici ${ }^{2}$, Jaroslav Masek ${ }^{3}$, Peter Marton ${ }^{4}$

${ }^{1}$ CETRA- Centre for Transport Research, University of Zilina, Slovakia, E-mail: cetra@uniza.sk

${ }^{2}$ Faculty of Mechanical Engineering, University of Zilina, Slovakia

${ }^{3}$ Faculty of Economics and Operation of Transport and Communications, University of Zilina, Slovakia

${ }^{4}$ Faculty of Management Science and Informatics, University of Zilina, Slovakia
} 
up of enlarging the vehicles of other means of transportation like the Jumbo and Giga-liners trucks.

VEL-Wagon pursued strongly the knowledge expansion in the following subjects:

- Future rail-road intermodal transportation market in Europe, especially when it comes to the utilisation of intermodal transport units (ITU) and freight wagons.

- Future wagonload transportation market in Europe, especially when it comes to conventional wagonloads and freight wagons utilisation.

- Infrastructure limitations, technical and economic, to extended wagon lengths, axle loads and loading gauges. In that context to identify and assess infrastructure capacity enlargements, implications of axle load increases, study suitable corridors and areas of influence of VEL-Wagon.

- Wagon enlargement possibilities, especially when it comes to length between bogie pivots, length between pivots and couplers, loading height and loading gauge for ITUs (also semitrailers) and conventional units, tare weight, heavy solicitations on frame as well as dynamic and static properties of such wagons.

- Economic equilibrium between wagon capacity increase, infrastructure requirements and freight market.

Regarding its effect on the infrastructure and operations, it should contribute to reduce the energy consumption per transported TEU, not only because of offering better loading factors but because of employing less deadweight and fewer axles, approximately $17 \%$ saving on energy consumption against a reference case, saving on maintenance (due to reduced number of axles) and reducing the noise emission (due to reduced number of axles).

\subsection{Constraints on VEL-WAGON design}

The use of large-sized wagons has a long tradition in the rail transport but nevertheless the application of large-scale container wagons for intermodal transport is not as widespread, as it would be appropriate. One of the regions, most strongly represented in the use of large-scale wagons in the world is the North America. In Europe, due to the differences in regulations in particular countries, as well as differences on the regional level, the use of proven solution is very difficult [2].

The specific requirements of different scenarios of the utilisation and technical constraints on the proposed VEL-WAGON output were summarized as follows - Table 1 .

It was concluded that the challenging situation from a technical point of view commences from $80 \mathrm{ft}$ onwards.

An initial analysis of the loading cases, comparing the articu-

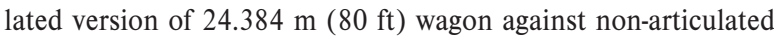
version of the same length yields led to the proposition of VELWAGON technical concept. The benefits of the proposed solution over different modalities are depicted in Fig. 1.

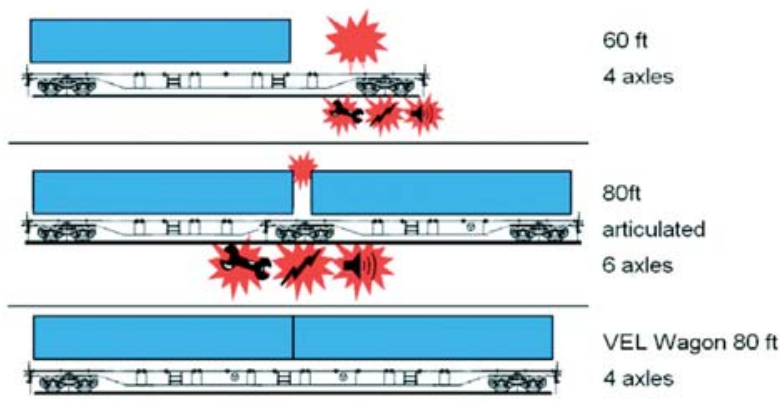

Fig. 1 Benefits of non-articulated VEL-WAGON concept over other possible technical solutions

(Source: TVP [3])

Main advantages and disadvantages of competing types of design are summarized in Table 2.

\begin{tabular}{|l|c|c|c|c|}
\hline \multicolumn{5}{|c|}{ Critical points of VEL-Wagons design } \\
\hline Wagon lenghth & \multicolumn{2}{|c|}{$24,384 \mathrm{~m}(80 \mathrm{ft})$} & \multicolumn{2}{c|}{$27,432 \mathrm{~m}(90 \mathrm{ft})$} \\
\hline Parameter & Advantage & Disadvantage & Advantage & Disadvantage \\
\hline Sag of car body & & + & & ++ \\
\hline Self-frequency of car body (frame) & & + & & ++ \\
\hline Kinematics outline (reduction Ec) & + & + & + & + \\
\hline Profile of railway & + & & & + \\
\hline S-curve transition & + & + & - & ++ \\
\hline Safety - quasi-static conditions $\mathrm{Y} / \mathrm{Q}=1.2$ & & + & & ++ \\
\hline Safety - during operation $\mathrm{Y} / \mathrm{Q}=0.8$ & & & & + \\
\hline
\end{tabular}


Non-articulated and articulated wagon's properties summarization (Source: TVP[3])

Table 2

\begin{tabular}{|c|c|}
\hline VEL-Wagon 24.384 m ( $80 \mathrm{ft}$ )-non-articulated & Articulated $24.384 \mathrm{~m}(80 \mathrm{ft})$ wagon \\
\hline $\begin{array}{l}\text { Advantages: } \\
\text { - lower tare mass } \\
\text { - fewer bogies } \\
\text { - effective for light transports } 6.096 \mathrm{~m} \text { (20ft), } 9.144 \mathrm{~m} \text { (30ft) and } \\
12.192 \mathrm{~m} \text { (40ft) units }\end{array}$ & $\begin{array}{l}\text { Advantages: } \\
\text { - big mass loading capacity, i.e. high load limit } \\
\text { - technical and design parameters } \\
\text { - effective for loading by all } 6.096 \mathrm{~m}(20 \mathrm{ft}) \text { and } 12.192 \mathrm{~m} \text { (40ft) units }\end{array}$ \\
\hline $\begin{array}{l}\text { Disadvantages: } \\
\text { - low mass loading capacity } \\
\text { - inefficiency for heavy } 6.096 \mathrm{~m}(20 \mathrm{ft}) \text { units, mainly up to } 22 \mathrm{t} \\
\text { - many design challenges } \\
\text { - structural strength, } \\
\text { - sag of skeleton wagon, } \\
\text { - natural frequency of vertical bending oscillation }\end{array}$ & $\begin{array}{l}\text { Disadvantages: } \\
\text { - higher tare mass } \\
\text { - higher investment cost } \\
\text { - inefficiency for loading by light } 6.096 \mathrm{~m}(20 \mathrm{ft}) \text { units and in } \\
\text { combination with } 9.144 \mathrm{~m}(30 \mathrm{ft}) \text { and } 12.192 \mathrm{~m} \text { (40ft) units }\end{array}$ \\
\hline
\end{tabular}

\subsection{Market analysis}

The volume of transported freight with the use of intermodal traffic is increasing, needing additional capacity and investment in additional cars. Transport of semitrailers by rail is also on its increase, so there is also need for additional pocket wagons, handling standard semitrailer length of $13.6 \mathrm{~m}$ to $13.7 \mathrm{~m}$. The use of longer containers of $12.192 \mathrm{~m}$ (40ft) and $13.716 \mathrm{~m}$ (45ft) of length is also increasing, so there is a growing need for the use of additional wagons, capable of their transport. The length of $13.716 \mathrm{~m}$ (45ft) does not fit with the more common lengths of $6.096 \mathrm{~m}$ (20ft) and $12.192 \mathrm{~m} \mathrm{(40ft),} \mathrm{but} \mathrm{it} \mathrm{closely} \mathrm{matches} 13.7 \mathrm{~m}$.

Thus, there is a need for new pocket wagons able to carry

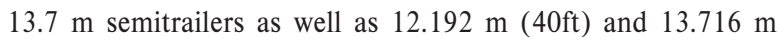
(45ft) containers and swap bodies.

After analysing the needs of intermodal traffics (hinterland and continental), it can be concluded that an $24.384 \mathrm{~m}$ ( $80 \mathrm{ft}$ ) container wagon for ISO-containers and swap bodies would offer an important improvement in terms of logistics and energy efficiency [4].

Longer loading lengths - $25.908(85 \mathrm{ft})$ and $27.432 \mathrm{~m}(90 \mathrm{ft})-$ could have an advantage too, but only if the $45 \mathrm{ft}$ unit is widely introduced and if it dominates in intermodal traffics, which is not the current case. A revision of this issue has to take place in approximately 5 years.

On the other hand, an $24.384 \mathrm{~m}$ (80ft) pocket wagon is an interesting solution for continental transports.
It would target mainstream traffic flows with great diversity on unit types, including semitrailers. However, the available solutions in the market [5] for the transportation of only semitrailers would offer a better performance at this time. This issue together

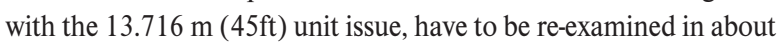
5 years.

Hence, a $24.384 \mathrm{~m}$ (80ft) wagon without pocket, suitable only for the transportation of containers and swap bodies, could be more competitive than other wagons in its market range.

\section{Design and modelling of VEL-WAGON}

As a result of the above mentioned analysis and simulations, the final variant of the VEL-WAGON parameters was chosen [6] and used for design of the model and its static and dynamic evaluation. This 4 - axle freight wagon for transportation of ISO containers and swap bodies - meets description TSI-WAG, valid regulations UIC, agreement on the reciprocal use of freight wagons in international traffic AVV (RIV), ERRI recommendations and EN standards. The wagon is suitable for transport of ISO containers $6.096 \mathrm{~m}$ (20ft), $7.9248 \mathrm{~m}$ (26ft), $9.144 \mathrm{~m}(30 \mathrm{ft}), 12.192 \mathrm{~m}$ (40ft) and $13.716 \mathrm{~m} \mathrm{(45ft)} \mathrm{according} \mathrm{to} \mathrm{UIC} \mathrm{592-2,} \mathrm{class} 1$ and swap bodies $12.192 \mathrm{~m}$ (40ft) according UIC 592-4.

The requirements specified in previous sections led to the design with geometric parameters of the wagon shown in Table 3:

Geometric parameters of VEL-WAGON (Source [6])

Table 3

\begin{tabular}{|l|l|l|l|}
\hline Length over buffers & $25940 \mathrm{~mm}$ & Draw gear height from top of rail & $1005+10-0 \mathrm{~mm}$ \\
\hline Loading length & $24700 \mathrm{~mm}$ & Wheel base of bogie & $1800 \mathrm{~mm}$ \\
\hline Pivots Distance & $18000 \mathrm{~mm}$ & Gauge of track & $1435 \mathrm{~mm}$ \\
\hline Lading height & $1090 \mathrm{~mm}$ & Wheel diameter & $920 \mathrm{~mm}$ \\
\hline Buffer axis height & $1025+10-0 \mathrm{~mm}$ & & \\
\hline
\end{tabular}


Weight parameters of the proposed wagon are as follows:

Mass of unoccupied coach $-21.5 \mathrm{t} \pm 3 \%$, maximum mass of occupied coach $90 \mathrm{t}$, maximum mass of load $68.5 \mathrm{t}$, maximum axle load $22.5 \mathrm{t}$.

The considered speed parameters are as follows:

Highest construction speed $120 \mathrm{~km} / \mathrm{h}$, highest operating speed for the weight of $20 \mathrm{t} /$ axle $-120 \mathrm{~km} / \mathrm{h}$, highest operating speed for the weight of $22.5 \mathrm{t} /$ axle $100 \mathrm{~km} / \mathrm{h}$

The 3D model of the proposed wagon design is shown in Fig. 2.
The model was used for extensive static and dynamic testing, which confirmed the feasibility of the proposed parameters and design.

\subsection{Static analysis}

The results of static analysis proved that the designed construction meets the EN 12663-2 technical requests. The virtual simulation tests (described in detail in [6]) were performed - Fig. 3:

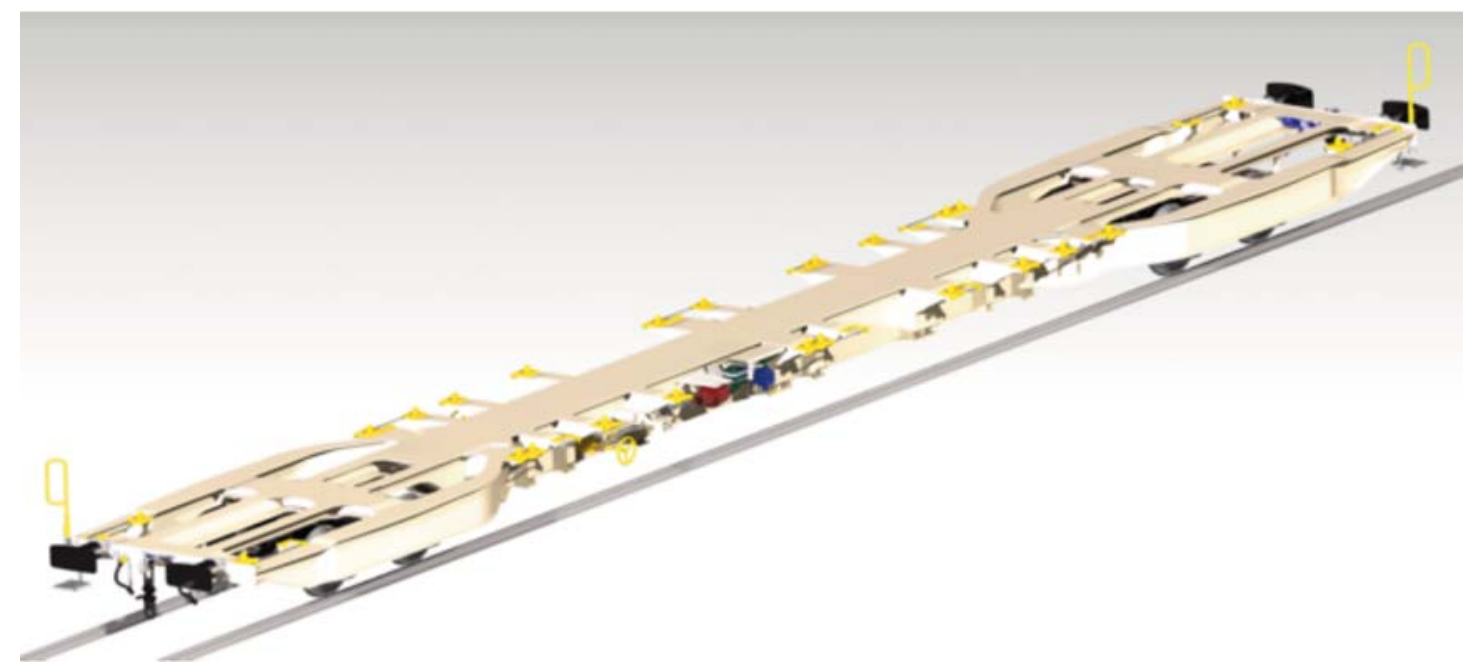

Fig. 2 VEL-WAGON 3D model used for modelling and simulations (Source [6])

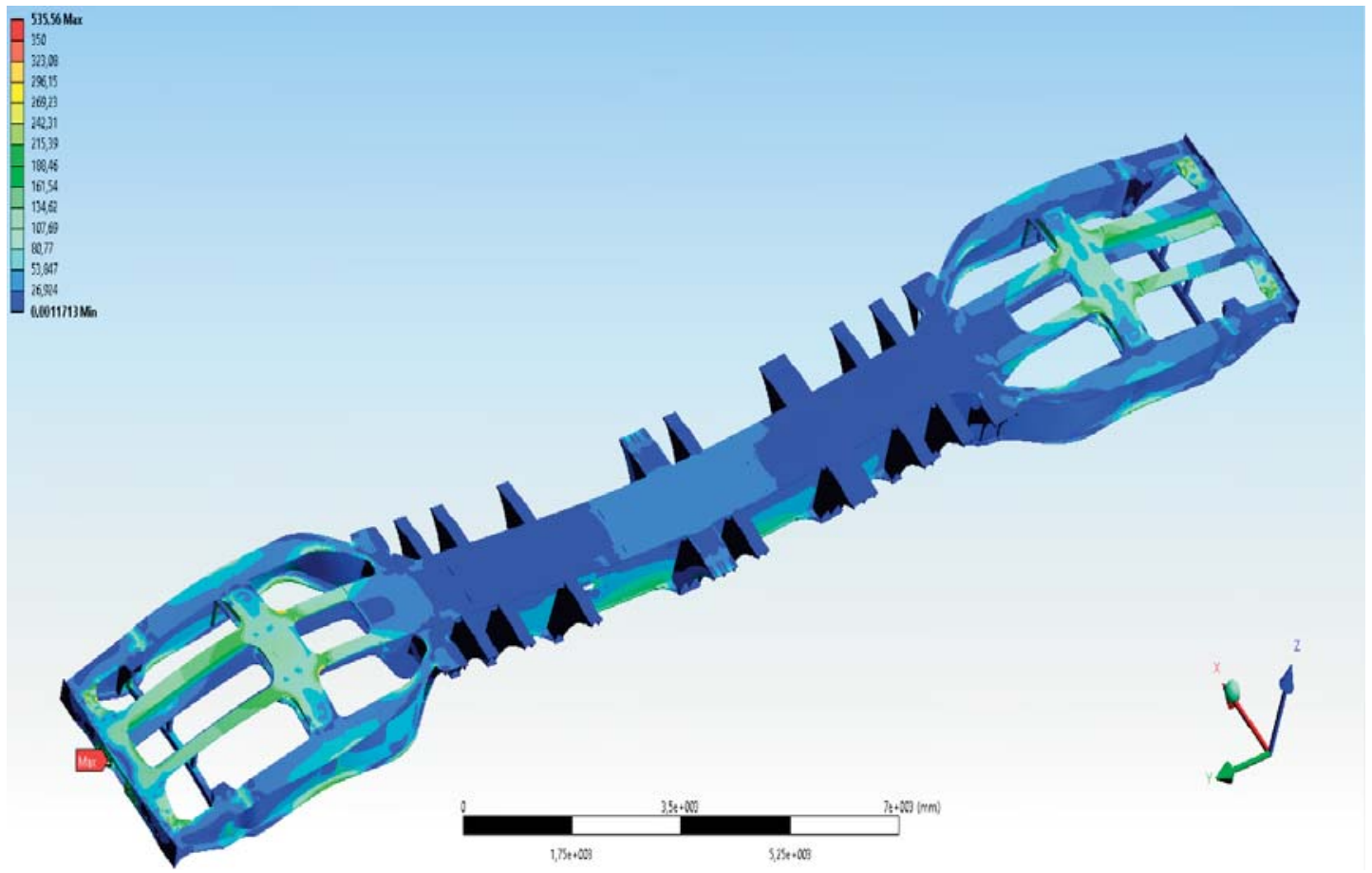

Fig. 3 Reduced stresses distribution in the wagon model (Source [6]) 
a. Modal analysis.

b. Wagon torsional stiffness computation.

c. Maximum vertical load force.

d. Wagon rising on one side - in the determined points.

e. All wagon rising.

f. Load combination- Press load in buffers and vertical load (loaded wagon).

g. Load combination- Pull load in coupling device and vertical load (loaded wagon).

In the first case, the eigenfrequency and eigenshapes (eigenvalues) were evaluated in the case, when the vehicle is bound with the bogie by means of ball pins and flexible sliding shoes. In the second case, the bogie torsional rigidity was investigated. This parameter has an important influence on the safety against derailment when the vehicle enters the track in a radius. This rigidity is relatively high which is caused by a closed design of a main wagon slide sill. The evaluated stresses exceed the permitted values only in some of the metal plates' connections which is caused by the local computational model mesh formulation or by the sharp edged crossing between plates. In the case of the real wagon production intention, it is recommended to pay increased attention to these spots from the point of view of production background (material quality, technology of welding, or parts connection) and so on. The results prove that the vehicle design meets EN 12663-2 requirements.

\subsection{Dynamic evaluation}

The dynamics analysis was performed in accordance with the technical parameters for two track sections in Cerhenice railway test track circuit. In the first case, the track with $450 \mathrm{~m}$ radius (see Fig. 4) was used and in the second case the straight track and the velocity of $100 \mathrm{~km} / \mathrm{h}$ were considered.

The geometric characteristics of railway wheel-set and track (Equivalent conicity and Delta-R function) were evaluated for the profiles contact couples S1002 for wheel, UIC60 and R65 rail with inclinations of 1:20 and 1:40 (straight track) and for the profiles contact couples S1002 for wheel, S49 rail with inclinations of $1: 20$ and $1: 40$ (radius R450 m).

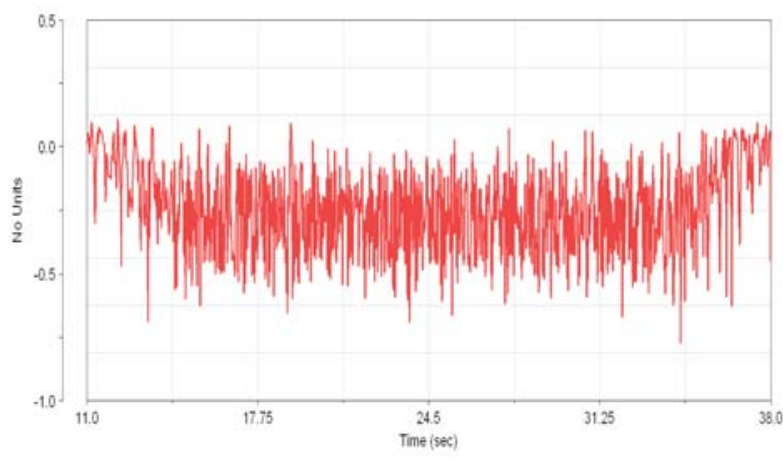

Fig. 4 Safety against derailment - curve - first wheel-set - $R=450 m$ (Source [6])
The geometric characteristics analysis for both cases was completed with the Equivalent conicity and Delta-R function characteristics set for different gauges values (in the interval of 1432-1448 $\mathrm{mm})$.

In order to analyse the safety against derailment, the accelerations, wheel vertical forces and leading lateral forces values were evaluated. In both cases, the safety against derailment values were in the interval of safe operation.

\section{Conclusions}

The performed simulations of the proposed VEL-Wagon use for the freight train composition instead of currently used wagons show that an $24.384 \mathrm{~m}$ (80ft) VEL-Wagon for intermodal transport can lead to better loading factor of trains ( $10 \%$ more TEU per length (vs. REF due to better arrangement of units).

The use of fewer axles per length implies:

- less energy consumption (decreased rolling resistance, less deadweight),

- less maintenance,

- less noise (fewer axles with increased axle load),

- better aerodynamics (fewer bogies and fewer gaps between containers),

- lower cost per transported unit load that is also a prerequisite for higher market share for intermodal transport.

The potential market of VEL-Wagon embraces the whole European Intermodal Market (Container transport and Swap Body transport) and part of the conventional railway freight market, the one dedicated to the light products.

A similar innovative wagon produced by Tatravagonka Poprad was implemented by METRANS, an intermodal and railway company which already bought an important batch of wagons. These units are however not the full version of VEL-Wagon, just a commercial application of its partial results.

VEL-Wagon implies a challenge for the technology because it opens the door for more capable wagons with lower tare and higher speed. It represents a gain in loading factors and a better arrangement for diverse and multiple loading schemes of containers and swap bodies. It is a wagon that is adapted better to the trend of having lighter containers, more prone to be volumetric loads than dense loads. Finally, it represents a challenge for the regulations, specifically when it comes to the certification of new wagons, whose dimensions go beyond the standards regulated by the norms. As the trends in the waterborne-, air- and road transport show, the vessels, planes and road vehicles tend to grow in size, so it can be expected that also longer, more capable wagons will be needed in the future.

The results of the project were submitted to the contest at the Green Corridors Day in Sweden among 31 contestants. VELWagon was chosen by the Jury and on 12.12. 2012 received from 

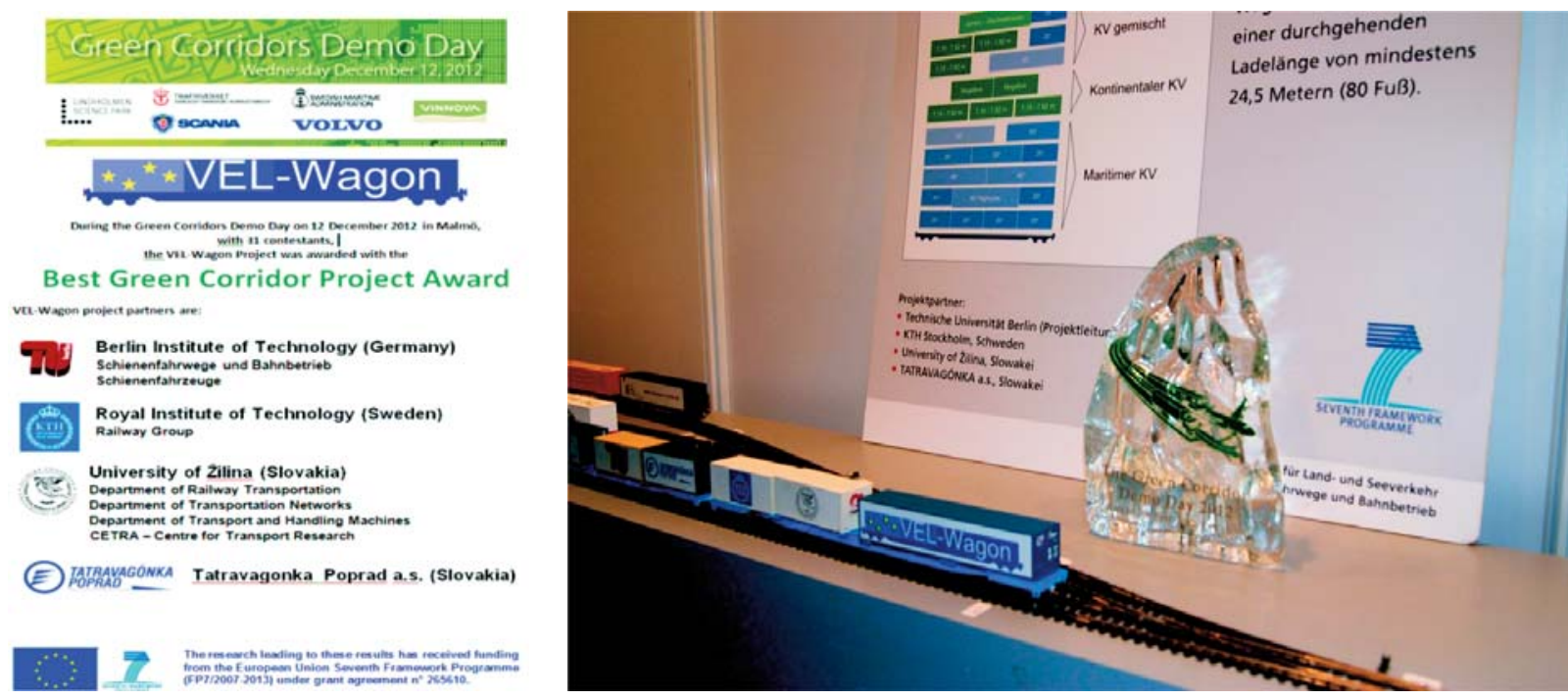

Fig. 5 Best Green Corridor Project Award

the Swedish Traffic Administration Trafikverket the award as the Best Green Corridor project - Fig. 5.

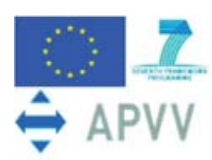

\section{Acknowledgement}

Project VEL-WAGON has been co-financed by the means provided by EU FP7 (2007-2013) grant No. 265610 and by APVV SR grant No.
DO-7RP-0027-10. This publication reflects the views only of the authors, and the European Commission cannot be held responsible for any use which may be made of the information contained therein.

\section{References}

[1] FP7 Call for project proposals FP7-SST-2010-RTD-1, http://ec.europa.eu/research/participants/portal/page/call_FP7?callIdentifier=FP7-TPT-2010-RTD-1\&specificProgram= COOPERATION\# wlp_call_FP7

[2] HILMOLA, O-P: European Railway Freight Transportation and Adaptation to Demand Decline Efficiency and Partial Productivity Analysis from Period of 1980-2003, Intern. J. of Productivity and Performance Management, vol. 56, No. 3, pp. 205-225, 2007

[3] VEL-WAGON Consortium: Deliverable Report 1.1: State of the art and concept drafting (http://www.vel-wagon.eu/index.php/ downloads?download $=4 \% 3$ Ad 11

[4] Deliverable Report 2.1: Intermodal application of VEL-Wagon (http://www.vel-wagon.eu/index.php/downloads?download=6\%3Ad21

[5] Deliverable Report 3.1 Study on railway business for VEL-Wagon and target costs

http://www.vel-wagon.eu/index.php/downloads?download=7\%3Adeliverable-report-31-study-on-railway-business-for-vel-wagon-andtarget-costs

[6] Deliverable Report 4.3.-4.4 Overview of 3D Model of the Wagon, Static and Dynamic Evaluations, internal VEL-WAGON document, VEL-WAGON Consortium, 2013 